\title{
THE BACTERIAL FLORA OF THE STOMACH AND SMALL INTESTINE IN CHILDREN WITH INTESTINAL OBSTRUCTION
}

\author{
BY \\ RUTH F. BISHOP and CHARLOTTE M. ANDERSON \\ From the Clinical Research Unit, Royal Children's Hospital, Melbourne
}

(RECEIVED FOR PUBLICATION MARCH 2, 1960)

The alimentary tract at birth is either sterile or contains only a few micro-organisms (Wilson and Miles, 1955). Within a few days of birth a profuse flora is established in the mouth and large intestine. However, the small intestine remains relatively free from micro-organisms throughout life (Cregan and Hayward, 1953; Anderson and Langford, 1958a). Thus in health it seems that some antibacterial mechanism is present which prevents a resident flora from becoming established in the small intestine.

The nature of this antibacterial mechanism is obscure. Cregan, Dunlop and Hayward (1953) have shown it to be independent of the gastric germicidal barrier. Anderson and Langford (1958a) have previously suggested that maintenance of normal intestinal motility is important. Evidence for this suggestion has been sought in the present study, which is an investigation of the flora of the small intestine in conditions where intestinal motility is affected by obstruction to the onward passage of intestinal contents. The patients examined included newborn and older children with obstructive lesions of differing aetiology and duration at differing sites along the small intestine.

A search of the literature did not reveal any previous investigation in newborn or older children or even any thorough investigation of the intestinal flora in adults with intestinal obstruction. Therefore this paper will also describe the extent and nature of the flora of the small intestine in children with intestinal obstruction. The results of a similar study in adults are reported elsewhere (Bishop and Allcock, 1960).

\section{Material and Methods}

Clinical Material. Twelve newborn babies aged from 1 to 7 days, in whom obstruction had been present at birth, were examined. These patients included one with volvulus of the stomach, two with duodenal atresia, three with jejunal atresia, one with Hirschsprung's disease and five with meconium ileus.

In addition 12 children aged from 10 days to 13 years in whom obstruction had developed acutely and one child of 17 months with subacute obstructive symptoms since birth were examined. The pathological conditions responsible for the obstruction and the duration of obstruction before operation were extremely varied and are recorded in Table 1.

Clinical findings relevant to the investigation were recorded for each patient on a specially compiled proforma. The data sought included duration and character of any vomiting, time of the last bowel action, details of any preoperative antibiotics and a description of the findings at operation.

Collection of Specimens. Specimens of intestinal contents were obtained in the following order from patients during operation for relief of the obstruction: from stomach via Ryle's tube; swab of free fluid in the peritoneal cavity; from small intestine approximately $10 \mathrm{~cm}$. distal to obstruction; from small intestine approximately $10 \mathrm{~cm}$. proximal to obstruction; from other levels of small intestine proximal to the obstruction, depending on the level of obstruction.

The contents of the small intestine were sampled using the following direct needling technique originally described by Cregan and Hayward (1953). At operation $2 \mathrm{ml}$. of sterile Ringer's solution were injected into the lumen of the bowel which was washed with this fluid by gently sucking back and forth with the syringe. The resultant diluted intestinal contents were then withdrawn. In order to keep the technique of sampling uniform, this procedure was always used even when the obstructed intestine contained sufficient fluid for direct aspiration.

Bacteriological Examinations. Usually within three hours of collection two drops (about $0.06 \mathrm{ml}$.) of each specimen were inoculated on to each of the following media: horse blood agar and plain desoxycholate agar incubated aerobically at $37^{\circ} \mathrm{C}$; ; horse blood agar incubated anaerobically at $37^{\circ} \mathrm{C}$. with $5-10 \%$ added $\mathrm{CO}_{2}$. The range of media and conditions of incubation 
TABLE 1

BACTERIAL FLORA IN INTESTINAL OBSTRUCTION IN BABIES AND OLDER CHILDREN

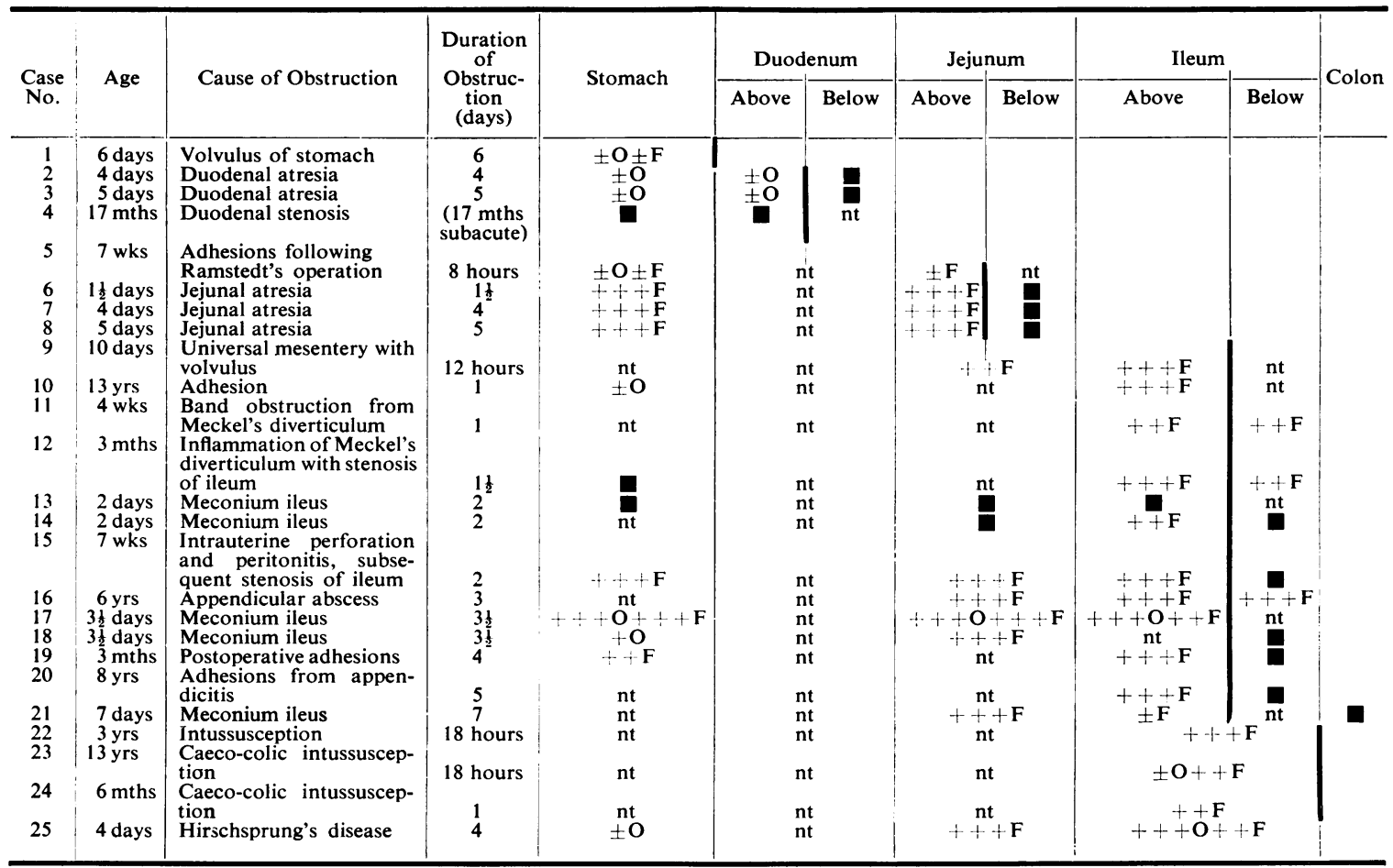

The vertical line in heavy type denotes level of obstruction.

$O$ denotes a flora of oral type.

$F$ denotes a flora of faecal type.

Plusses indicate degree of growth: \pm and + denote transient flora $;++$ and +++ denote resident flora (see text).

nt denotes not tested.

denotes sterile.

were chosen so that the growth requirements of all bacteria likely to occur in the intestinal tract would be satisfied. Direct smears were always examined as a check on the adequacy of conditions of culture. A standard plating technique was used (Cregan and Hayward, 1953) and the degree of growth was graded from \pm to +++ . A scanty growth $( \pm$ or + ) was regarded as a transient flora unable to multiply at the site sampled. A profuse growth $(++$ or +++$)$ was regarded as a resident flora. As well as the plating technique, the criteria for interpretation of quantitative results described fully by Cregan and Hayward (1953) were followed exactly.

\section{Results}

Table 1 shows quantitative results from the 25 patients examined. Table 2 shows qualitative results from the 19 children with an abnormal profuse flora $(++$ or +++$)$ in the small intestine. In both Tables the results from new born and older children have been combined since no bacterio- logical difference between these two groups was observed.

Specimens Proximal to the Point of Obstruction. Quantitative and qualitative results from specimens proximal to the point of obstruction differed with the level of obstruction. All specimens from four children with obstruction proximal to the duodenojejunal flexure (Cases 1-4) were either sterile or contained only a scanty flora usually of oral type. By contrast in almost all (19 out of 21) children with obstruction distal to the duodenal-jejunal flexure (Cases 5-25) a profuse flora of faecal type was present in the small intestine above the point of obstruction. Stomach specimens from 12 of these children were also examined. Six yielded a profuse faecal flora and six were either sterile or yielded only a scanty flora of oral type.

Since 12 children received antibiotics parenterally before operation it was important to be sure that 
TABLE 2

BACTERIAL FLORA OF THE SMALL INTESTINE IN ACUTE INTESTINAL OBSTRUCTION

\begin{tabular}{l|c|l|c}
\hline \multicolumn{1}{|c|}{ Faecal Type Organisms } & $\begin{array}{c}\text { No. of } \\
\text { Times } \\
\text { Isolated }\end{array}$ & Oral Type Organisms & $\begin{array}{c}\text { No. of } \\
\text { Times } \\
\text { Isolated }\end{array}$ \\
\hline Bact. coli type I & 15 & Staph. saprophyticus & 4 \\
Cl. welchii & 9 & Staph. afermentans & 2 \\
Strep. faecalis & 7 & Staph. lactis & 2 \\
Bacteroides sp. & 6 & Staph. aureus & 2 \\
Paracolon sp. & 5 & H. parainfluenzae & 2 \\
Veillonella gazogenes & 4 & Strep. agalactiae & 2 \\
Bact. aerogenes type I & 3 & Strep. mitis & 5 \\
Bact. coli irregular type & 2 & Strep. S.B.E. & 1 \\
Bact. coli intermediate & 2 & C. xerosis & 1 \\
type I & 2 & & \\
Strep. liquefaciens & 2 & & \\
Strep. zymogenes & 1 & & \\
Cl. fallax & 1 & & \\
Cl. paraputrificum & 1 & & \\
Cl. multifermentans & 1 & & \\
Pr. mirabilis & 1 & & \\
Pr. vulgaris & 1 & & \\
Veillonella parvula & 1 & & \\
Achrombacter sp. & 1 & \\
Alcaligenes faecalis & 1 & \\
Candida albicans & & \\
\hline
\end{tabular}

Number of cases with abnormal resident flora $=19$.

this had no effect on the bacteriological results. The antibiotics used were tetracycline or penicillin and streptomycin given intramuscularly or intravenously as one dose (Cases 6, 7, 11, 13, 14, 15 and 17) or as a more prolonged course (Cases 2, 8, 10, 16 and 19). The small intestine of five of the former and four of the latter contained a profuse faecal flora at operation, so that it is unlikely that the results from the remaining three, that yielded only scanty flora, could be attributed to suppression of bacterial growth in the bowel lumen by the preoperative parenteral antibiotics.

Specimens Distal to the Point of Obstruction. Unlike the proximal specimens, results from specimens distal to the point of obstruction were quantitatively and qualitatively independent of level of obstruction. Of 14 samples from below the obstruction, 11 were sterile. The remaining three (Cases 11, 12 and 16) yielded a profuse faecal flora but the intestinal lumen of each of these three children was only partially obstructed and it was concluded that the results were invalid due to contamination with fluid from above the point of obstruction.

Peritoneal Swabs. These specimens were obtained from eight children and were always sterile when the bowel was viable. In three children there was a portion of non-viable bowel (Cases 9, 11 and 16). In one of these (Case 9) the peritoneal swab was sterile. In the other two a faecal flora was isolated and was found to be qualitatively similar to that present in the intestinal lumen.
Qualitative Results. Table 2 shows that organisms of faecal type were common in the small intestine of the 19 patients yielding abnormal quantitative $(++$ or +++$)$ results. Oral type organisms were only occasionally isolated. Bact. coli type 1 was present in 15 of the 19 children. Cl. welchii was present in less than half of the cases examined, an incidence much less than that found in a similar study in adults (Bishop and Allcock, 1960). None of the faecal type organisms were outside the range of those likely to occur in the healthy large intestine.

\section{Discussion}

A search of the literature of the past 60 years has not revealed any detailed investigation of the bacterial flora of the small intestine in intestinal obstruction either in children or in adults. Williams $(1926,1927)$ examined vomitus and small intestinal contents from adults with intestinal obstruction. However, his samples of small intestinal contents were restricted to the point of intestinal resection and the bacteriological techniques were directed mainly towards isolation of $\mathrm{Cl}$. welchii. In the present investigation the technique of sampling allowed several levels of intestine to be examined even when no intestine was resected and the bacteriological techniques used were directed at isolating and fully identifying all species of bacteria present.

No difference was found between the results from babies and those from older children. The overall results from all children are therefore presented diagrammatically in Figs. 1 and 2 . When obstruction was present proximal to the duodenojejunal flexure (Fig. 1) the small intestine and stomach remained bacteriologically normal, i.e. were either sterile or contained only a scanty flora. When obstruction was present distal to the duodenojejunal flexure a profuse faecal flora was found above the point of obstruction (Fig. 2). Regardless of the level of obstruction, small intestine distal to the point of complete obstruction remained bacteriologically

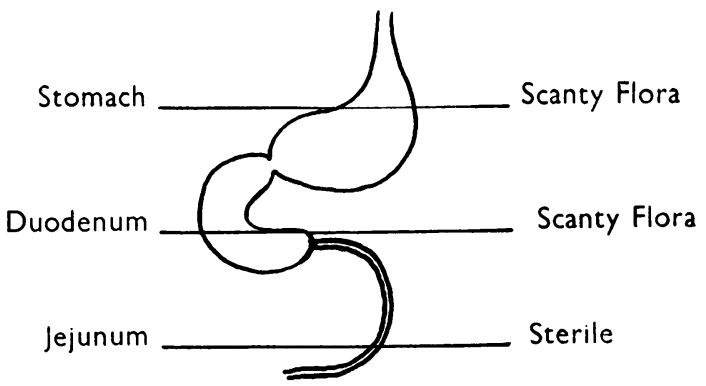

FIG. 1.-Extent of flora in gastro-intestinal tract when obstruction was in the region of duodeno-jejunal flexure. 


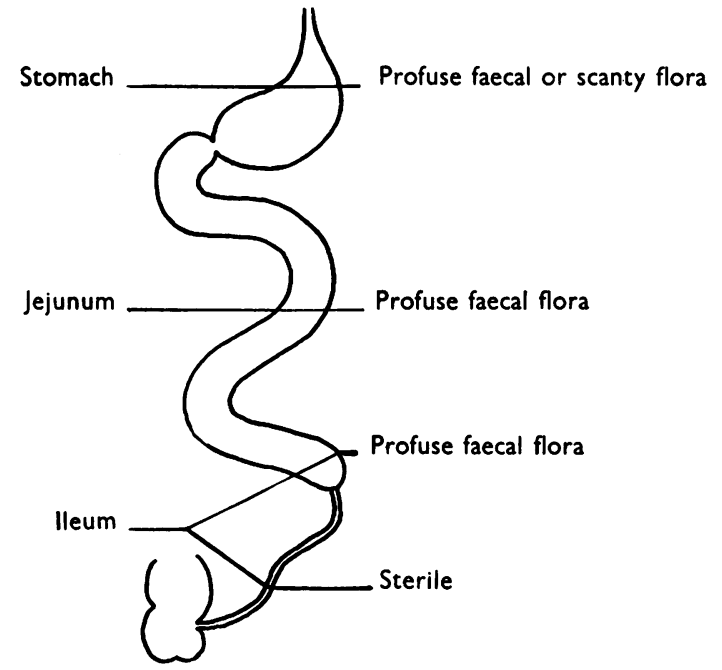

FIG. 2.-Extent of flora in gastro-intestinal tract when obstruction distal tọ duodeno-jejunal flexure.

normal. This was not necessarily so when obstruction was incomplete. These results indicate that the profuse faecal flora present in the small intestine above an obstruction is derived by ingestion and not by retrograde spread from the colon. This is confirmed by the results of Bishop and Allcock (1960) in adult patients.

Since the profuse faecal flora present in the small intestine above an obstruction is derived by ingestion, it follows that even in health faecal organisms frequently escape the gastric germicidal barrier and contaminate the small intestine. However, faecal organisms do not proliferate in the healthy small intestine since it has been shown to contain only a scanty flora usually of oral type (Cregan and Hayward, 1953; Cook, Elliott, Elliot-Smith, Frisby and Gardner, 1957; Anderson and Langford, 1958a). It is surprising that these organisms do not proliferate in the healthy small intestine since conditions of $p \mathrm{H}$, of temperature and oxygen tension are favourable to their growth. Thus in health some mechanism must prevent the growth of a profuse flora in the small intestine.

The nature of this mechanism is not well understood. It has been shown to be independent of the gastric germicidal barrier (Cregan et al., 1953) and therefore must depend on other factors, perhaps either chemical or mechanical, present in the small intestine. It is possible that the small intestine secretes a chemical which is either bacteriostatic or bactericidal. However, the absence of pancreatic secretion (Anderson and Langford, 1958a), or of bile (Anderson and Langford, 1958b) does not affect the flora of the small intestine and no other secretion with antibacterial activity against the species of micro-organisms isolated in this study has yet been demonstrated. If a chemical antibacterial substance exists in the small intestine it must be neutralized in some way in the terminal ileum or colon. Alternatively, it is possible that the antibacterial mechanism is dependent on mechanical factors such as constant secretion and movement of intestinal contents which might wash through all contaminating bacteria at a rate precluding colonization.

The results of this study do not allow any firm decision as to whether chemical or mechanical factors are more important. The pattern of results shown in Fig. 1 could be explained by chemical factors since it is likely that at this high level the acidity of stomach secretions is able to prevent growth of micro-organisms in the small intestine. However, the results shown in Fig. 2 could equally well be explained by disturbance of chemical or mechanical factors. The alteration in local conditions or the distension which accompanies obstruction of the small intestine could inhibit secretion of an as yet unknown chemical antibacterial substance. But it is also possible and seems more likely that the effect of obstruction on bacterial content of the small intestine could be explained by disturbance of mechanical factors alone, i.e. by the arrest of onward passage of intestinal contents and alteration of motility patterns.

From the results it is clear that parenteral antibiotics do not substantially affect the flora found above an obstruction. However, as the peritoneal swabs in those patients with non-viable bowel showed a flora of the same type as the bowel content, parenteral antibiotics may be of value in preventing peritoneal or blood spread of these organisms or of organisms spilled at operation.

\section{Summary}

The bacterial flora of the small intestine in 12 newborn and 13 older children with intestinal obstruction has been studied.

A profuse flora predominantly of faecal type was demonstrated above the point of obstruction when this was below the duodeno-jejunal flexure.

The small intestine below the site of complete obstruction was sterile.

The source of infection above an obstruction is considered to be ingestion and not retrograde spread from the colon.

The antibacterial mechanism of the small intestine is disturbed when the intestinal lumen is obstructed and reasons for this disturbance are briefly discussed. 
We would like to thank the surgeons of the Royal Children's Hospital, Melbourne, for their cooperation and also the medical and surgical registrars, particularly Dr. David Danks, for their help.

\section{REFERENCES}

Anderson, C. M. and Langford, R. F. (1958a). Bacterial content of small intestine of children in health, in coeliac disease and in fibrocystic disease of pancreas. Brit. med. J., 1, 803.

(1958b). The bacterial flora of the small intestine in normal children and children with malabsorption and steatorrhea. Proceedings of the World Congress of Gastroenterology, Washington, D.C., p. 438.

Bishop, R. F and Allcock, E. A. (1960). Bacterial flora of the small intestine in acute intestinal obstruction. Brit. med. J., 1, 766.
Cook, J., Elliott, C., Elliot-Smith, A., Frisby, B. R. and Gardner, A. M. N. (1957), Staphylococcal diarrhoea: with an account of two outbreaks in the same hospital. Ibid., 1, 542.

Cregan, J. and Hayward, N. J. (1953). The bacterial content of the healthy human small intestine. Ibid., 1, 1356.

_- Dunlop, E. E. and Hayward, N. J. (1953). The bacterial content of human small intestine in disease of the stomach. Ibid., 2, 1248.

Williams, B. W. (1926). The importance of toxaemia due to anaerobic organisms in intestinal obstruction and peritonitis. Brit. J. Surg., 14, 295.

- (1927). Importance of toxaemia due to anaerobic organisms in acute intestinal obstruction and peritonitis. Lancet, 1, 907.

Wilson, G. S. and Miles, A. A. (1955). Topley and Wilson's Principles of Bacteriology and Immunity, 4th ed. Arnold, 